\title{
Impact of Non-compliance with Antihypertensive Management on Development of Stroke among Hypertensive Patients: A Case-Control Study
}

\author{
K. L. Ajee ${ }^{1}$, A. Y. Kshirsagar ${ }^{2}$ \\ 'Department of Medical-Surgical Nursing, INHS Sanjivani, Kochi, Kerala, India, ${ }^{2}$ Department of Surgery, Krishna Institute of Medical Science, Karad, Maharashtra, India
}

\section{Abstract}

Introduction: Hypertension and stroke are two major health problems in India. Uncontrolled hypertension increases the chances of development of stroke. The main reason for inadequate control of blood pressure is non-compliance to the treatment regimen; both pharmacological and behavioral. The aim and objective of the study were to assess the relationship between non-compliance to antihypertensive management and development of stroke. It was also aimed to identify non-compliance among patients with hypertension.

Materials and Methods: This was a one to two individually matched case-control study conducted among 139 cases and 278 controls in a tertiary care hospital of West Bengal. A self-developed validated questionnaire was used to obtain information regarding compliance from hypertensive people and patients with stroke. Antihypertensive management regimen included compliance to medication, dietary restrictions, exercise, cessation of smoking, and cessation or restriction of alcohol intake. Medication adherence was assessed using four-item questionnaires on a five-point Likert scale. A score $>9$ was considered as non-compliant. Other components were assessed with "Yes" or "No" questions. A total score of four out of five were considered as compliant to antihypertensive management. Descriptive statistics such as mean, percentage, and inferential statistics such as Mantel-Haenszel odds ratio $\left(\mathrm{OR}_{\mathrm{MH}}\right)$ were used in this study.

Results: The mean age of cases was 51.62 ( \pm 5.1 standard deviation $[\mathrm{SD}])$ and that of controls was 54.79 ( \pm 4.1 SD). Sample characteristics were equally distributed among cases and controls except for educational qualification and income. Nearly half (46\%) of the sample were in the age group of 56-60 years of age. The exposure to non-compliance increases the odds of getting a stroke and was highly significant $(P<0.05)$.

Conclusion: There is a significant association between non-compliance to antihypertensive management and development of stroke. It is important to conduct an awareness program among hypertensive people regarding the importance of compliance to the treatment regimen. More consideration and care should be given to enhance the behavioral aspects of the management of hypertension to improve compliance.

Keywords: Hypertension, non-compliance, stroke

\section{INTRODUCTION}

Hypertension is the most important risk factor for worldwide morbidity and mortality and a major public health problem which affects $20 \%$ of the adult population, responsible for over $70 \%$ of stroke in women and $40 \%$ in men and

\begin{tabular}{|l|}
\hline \multicolumn{1}{|c|}{ Access this article online } \\
\hline Website: http://innovationalpublishers.com/Journal/ijnmi \\
\hline ISSN No: $2656-4656$ \\
DOI: $10.31690 /$ ijnmi/43 \\
\hline
\end{tabular}

the single most important persuasive threat issue for stroke..$^{[1-4]}$ Hypertension is one of the major mainsprings which contributes to disability, health care costs, and stroke mortality ${ }^{[5,6]}$ and one of the major but preventable or controllable risk factors for stroke. Low adherence to antihypertensive therapy is found to be associated with uncontrollable hypertension. ${ }^{[7]}$ The most common neurological disease "Stroke" is not a medical jargon for the layman in the present scenario. Being the second cause of death due to non-communicable disease, stroke is a major health problem in many countries ${ }^{[8-10]}$ Stroke, a feasible outcome of hypertension, often leads to death and 
disability. ${ }^{[11-13]}$ The echelon of disability varies from patient to patient according to the type of stroke suffered, the part of the brain affected, and the size of the damaged area. In developing countries, stroke remains a prime public health problem. Stroke, also called brain attack, occurs when the blood flow to an area of the brain is interrupted, resulting in some degree of permanent neurological damage. ${ }^{[14]}$

It occurs when part of the brain does not receive the needed blood flow for one of two reasons either the blood supply to part of the brain is suddenly interrupted, or because a blood vessel in the brain ruptures and blood invades the surrounding areas. Without the blood supply, the brain cells start to die (cerebral infarction), leading to brain damage. Approximately two million brain cells die every minute during a stroke, which increases the risk of brain damage, disability, and death. Stroke is the third leading cause of death in the United States and the UK after heart disease and cancer, and the number one cause of adult disability. ${ }^{[15]}$ Many studies conducted at the UK and the Netherlands showed that quality control of hypertension is strongly related to the occurrence of stroke. ${ }^{[16-18]}$ Even though both systolic and diastolic hypertensions are associated with increased risk for the stroke, systolic blood pressure (BP) is found to be more dangerous for developing the cerebrovascular disease. ${ }^{[19]}$ Clinical trials show that antihypertensive therapy is strongly associated with $35-45 \%$ mean reduction in stroke incidence. ${ }^{[20]}$ This antihypertensive treatment can be pharmacological or non-pharmacological.

Thus, the aim of the present study was to assess whether individuals with low adherence to antihypertensive management are at risk of developing stroke.

\section{Materials and Methods}

\section{Research design}

This study adopted a quantitative approach using case-control retrospective study design. The subjects were divided into cases and control as per sample selection criteria. It was conducted among 139 patients diagnosed to have a stroke and was admitted in a multidisciplinary tertiary care teaching and referral hospital in West Bengal affiliated to West Bengal University of Health Sciences over a period of 6 months from March to August 2016.

The sample size was calculated for an estimated OR of two and expecting a $20 \%$ exposure among controls with $90 \%$ power and $5 \%$ one-sided alpha $(\alpha)$ risk. The case to control ratio was two. The calculated sample size for case was 139 . Consecutive sampling technique was used to collect cases. To detect small differences between two groups and to compensate the potential loss of controls, it was decided to select one to two matched controls from the same settings. Hence, 278 hypertensive patients were recruited as controls that were attending outpatient department (OPD) from the same setting and were individually matched.
The cases and controls were individually matched by age ( \pm 2 years), sex, starting point of medication, time of diagnosis of hypertension, enrolment location, residential status, and use of complementary and alternative medicine.

\section{Sample selection criteria for cases}

The patients irrespective of sex and aged 40-60 years, and admitted ( $\geq 3$ days) in acute ward/ICU with a physician made diagnosis of $1^{\text {st }}$ time stroke, and a computed tomography head finding suggestive of ischemic or hemorrhagic stroke and with a history of hypertension only on antihypertensive treatment for $>1$ year were included in the study. The age group was restricted up to 60 years as a stroke below this age is preventable. ${ }^{[21]}$

\section{Sample selection criteria for controls}

Hypertensive patients with no other comorbidities or any history of stroke or stroke-like symptoms and on antihypertensive treatment for $>1$ year duration attending medical OPD of same tertiary care hospital.

\section{Exclusion criteria}

Patients with any systemic diseases other than hypertension and do not have a recorded BP reading on their medical

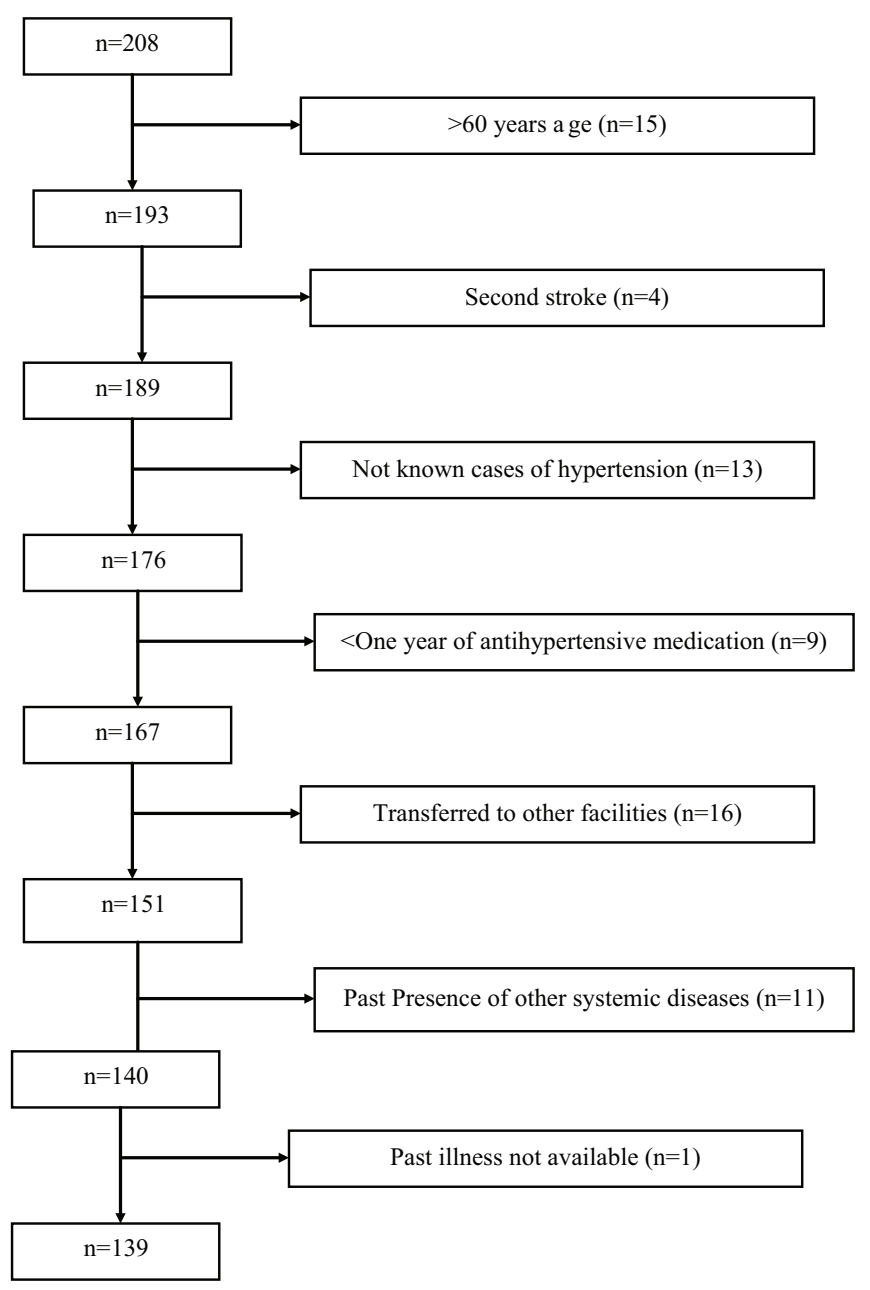

Figure 1: Patients flow into the study 
record or diary. Patients who are not able to give consent or not able to obtain consent from a proxy respondent and those who participated in the pilot study were excluded from the study. Proxy respondents in this study meant either spouse or a first degree relative living in the same home and were aware about patients' past health status including medication history.

A total of 214 patients with stroke were admitted from March to August 2016, and 75 cases were excluded due to various reasons, as shown in the flow chart [Figure 1].

\section{Tool development}

A self-developed structured questionnaire was used to collect socio-demographic data and compliance status. The first part of the questionnaire dealt with personal information such as age, gender, marital status, education, occupation, monthly income, and body mass index.

The second part consisted of a questionnaire to assess the compliance level to antihypertensive management. Compliance to five components of antihypertensive management regimen was assessed separately using a questionnaire adopted from various literature.

a. Medication adherence was assessed using a four-item questionnaire on a five-point Likert scale ranging from 0 to 4 . A score $>9$ was considered as non-compliant

b. Adherence to dietary restrictions was assessed using "Yes" or "No" questions. Dietary restrictions in this study mean following dietary assistance to stop hypertension

c. Adherence to modification of alcohol intake was assessed using "Yes" or "No" questions. Alcohol intake was categorized in to never/former drinker and current drinker

d. Adherence to exercise was assessed using "Yes" or "No" questions. Patients were categorized as physically active if they were involved in moderate to strenuous exercises at least 3 days/week or progressively inactive

e. Adherence to the cessation of smoking was assessed with "Yes" or "No" questions. Smoking status was defined as never, former, or current smoker. Current smokers were individuals who smoked any tobacco in the past 12 months and included those who had quit within the past 1 year. Former smokers were defined as those who had quit more than a year earlier.

A well informed written consent was taken either from patients or from the proxy respondent. Institutional Ethical Clearance was obtained before data collection.

Data were collected over a period of 6 months. The information was collected either from the patient or a proxy respondent in cases group and from patients in the control group. Even though stress management is an important component of antihypertensive management regimen, it was not included in this study as stress is highly subjective and in some cases, proxy respondents were the informers. In the setting where the study was conducted, all hypertensive patients were asked to maintain a diary or a notebook at the time of registration.
An identification mark was placed on the diary or notebook of pilot study sample so as to identify and exclude them from the main study.

\section{Statistical analysis}

Differential statistics such as mean and percentage were calculated for demographic data and compliance level. The relationship of non-compliance to antihypertensive management and occurrence of stroke was carried out using matched Mantel-Haenszel odds ratio $\left(\mathrm{OR}_{\mathrm{MH}}\right)$. This was used to control the confounding effect as the controls are not selected randomly but selected according to matching criteria. Hence, to control the superimposed confounding factors, we used a stratified analysis. The matched odds ratio is calculated using pairs instead of individuals, and a pair is considered as a

Table 1a: Demographic characteristics

\begin{tabular}{|c|c|c|}
\hline \multirow[t]{2}{*}{ Variables } & Case $(n=139)$ & \multirow{2}{*}{$\begin{array}{c}\text { Control }(n=278) \\
n(\%)\end{array}$} \\
\hline & $n(\%)$ & \\
\hline \multicolumn{3}{|l|}{ Age (years) } \\
\hline $41-45$ & $6(4)$ & $13(5)$ \\
\hline $46-50$ & $14(10)$ & $30(11)$ \\
\hline $51-55$ & $55(40)$ & $107(38)$ \\
\hline $56-60$ & $64(46)$ & $128(46)$ \\
\hline \multicolumn{3}{|l|}{ Gender } \\
\hline Male & $124(89)$ & $248(89)$ \\
\hline Female & $15(11)$ & $30(11)$ \\
\hline \multicolumn{3}{|l|}{ Marital status } \\
\hline Married & $116(83)$ & $234(84)$ \\
\hline Single & 2 & - \\
\hline Cohabitant & - & - \\
\hline Widow/widower/divorce & $21(15)$ & $44(16)$ \\
\hline \multicolumn{3}{|l|}{ Level of education } \\
\hline No formal education & $6(4)$ & $11(4)$ \\
\hline Primary & $23(17)$ & $60(21)$ \\
\hline Secondary & $64(46)$ & $122(44)$ \\
\hline Higher secondary & $16(11)$ & $19(07)$ \\
\hline Diploma/degree & $22(16)$ & $49(18)$ \\
\hline Others & $8(6)$ & $17(6)$ \\
\hline \multicolumn{3}{|l|}{ Occupation } \\
\hline Skilled & $114(82)$ & $218(78)$ \\
\hline Unskilled & $9(6)$ & $11(4)$ \\
\hline Professional & $16(12)$ & 49 (18) \\
\hline \multicolumn{3}{|l|}{ Income (Rs) } \\
\hline$<5000 /$ month & - & - \\
\hline $5001-10,000$ & $3(2)$ & - \\
\hline $10,001-15,000$ & $40(29)$ & $56(20)$ \\
\hline$>15,000$ & $96(69)$ & $222(80)$ \\
\hline \multicolumn{3}{|l|}{ Residence } \\
\hline Urban & $69(50)$ & $150(54)$ \\
\hline Rural & $70(50)$ & $128(46)$ \\
\hline \multicolumn{3}{|l|}{ BMI $\left(\mathrm{kg} / \mathrm{m}^{2}\right)$} \\
\hline Normal & $33(24)$ & $85(30)$ \\
\hline Overweight & $79(57)$ & $144(52)$ \\
\hline Obese & $27(19)$ & $49(18)$ \\
\hline \multicolumn{3}{|l|}{ Family h/o stroke } \\
\hline Yes & $91(65)$ & $118(42)$ \\
\hline No & $48(35)$ & $160(58)$ \\
\hline \multicolumn{3}{|l|}{ Blood pressure } \\
\hline Normotensive & $5(4)$ & $158(57)$ \\
\hline Hypertensive & $39(28)$ & $84(30)$ \\
\hline Hypotensive & $95(68)$ & $36(13)$ \\
\hline \multicolumn{3}{|l|}{ Cholesterol level } \\
\hline Normal & $19(14)$ & $203(73)$ \\
\hline Hypercholesterolemia & $120(86)$ & $75(27)$ \\
\hline
\end{tabular}


stratum. In this study, we had six strata - two concordant and four discordant strata.

\section{RESULTS}

The collected data were tabulated, analyzed, and interpreted.

\section{Demographic characteristics}

Table 1a shows the distribution of cases and controls according to their demographic characteristics.

Table 1a-c show the distribution of cases and controls according to demographic characteristics. As it was an individually matched case-control study, sample characteristics were equally distributed among cases and controls except for educational qualification and income. Nearly half (46\%) of the sample were in the age group of 56-60 years of age. The mean age of cases was $51.62( \pm 5.1 \mathrm{SD})$ and that of controls was $54.79( \pm 4.1 \mathrm{SD})$.

The relationship between non-compliance to antihypertensive management and risk for development of stroke is shown in Table 2. In this study, the $\mathrm{OR}_{\mathrm{MH}}$ explains that the exposure to non-compliance increases the odds of getting stroke and is highly significant; thus, the null hypothesis $\mathrm{OR}_{\mathrm{MH}}=1$ is rejected. Table 2 illustrates the compliance pattern to antihypertensive management in total and compliance to five components separately. Even though there were four types of discordant pairs, for computing the odds ratio it is made into two discordant data as shown below.

The discordant pairs are:

1. Case compliant and both controls non-compliant

2. Case compliant and one control are non-compliant

3. Case non-compliant and both control compliant

4. Case non-compliant and one control compliant.

This was combined and formed to:

a. Case compliant and control non- compliant

b. Case non-compliant and control compliant.

Table 1b: Sample characteristics

\begin{tabular}{|c|c|c|}
\hline \multirow[t]{2}{*}{ Variables } & \multirow{2}{*}{$\begin{array}{c}\text { Case }(n=139) \\
n(\%)\end{array}$} & \multirow{2}{*}{$\begin{array}{c}\text { Control }(n=278) \\
n(\%)\end{array}$} \\
\hline & & \\
\hline \multicolumn{3}{|c|}{ Duration of hypertension (years) } \\
\hline $1-3$ & $28(20)$ & $56(20)$ \\
\hline $3.1-5$ & $35(25)$ & $70(25)$ \\
\hline$>5$ & $76(55)$ & $152(55)$ \\
\hline \multicolumn{3}{|c|}{ Use of CAM } \\
\hline Yes & $59(42)$ & $118(42)$ \\
\hline No & $80(58)$ & $160(58)$ \\
\hline \multicolumn{3}{|c|}{ Experience stress } \\
\hline Yes & $86(62)$ & $190(68)$ \\
\hline No & $53(38)$ & $88(32)$ \\
\hline
\end{tabular}

Table 1c: Mean age of the sample

\begin{tabular}{llccc}
\hline S. No. & Sample & Frequency $(\boldsymbol{n})$ & Mean (years) & SD \\
\hline 1. & Case & 139 & 51.62 & 5.1 \\
2. & Control & 278 & 54.79 & 4.1 \\
\hline
\end{tabular}

\section{Discussion}

There are many epidemiological and clinical studies proved the continuous and direct relationship that exists between hypertension and stroke. ${ }^{[22]}$ Studies showed that there was a significant association between non-compliance to antihypertensive management and stroke. ${ }^{[23-25]}$ The present individually matched case-control study assessed the relationship between non-compliance to antihypertensive management and stroke. The objective of the study was to assess the relation between non-compliance to antihypertensive management and the development of stroke. The results of the study revealed a strong relationship between non-compliance to antihypertensive management and stroke.

\section{According to demographic characteristics studied}

Nearly half $(46 \%)$ of the participants were in the age group of 56-60 years. Approximately $90 \%$ of the participants were male and the majority (83\%) were married. Secondary education was the highest level of education among $46 \%$ of the sample and most $(82 \%)$ were skilled workers. Residential status was almost similar among cases and controls. More than half $(57 \%)$ had overweight. Among cases, $65 \%$ had a family history of the stroke whereas $58 \%$ of controls did not have a family history of stroke. Most $(86 \%)$ of the cases had hypercholesterolemia. This supports the fact that those having a family history of stroke and having a high level of cholesterol have a greater risk for stroke. ${ }^{[26,27]}$

The study shows that exposure to non-compliance to antihypertensive management regimen increases the odds of developing stroke and was statistically significant $\left(\mathrm{MH}{ }_{\mathrm{OR}}\right.$ 2.8462, $P<0.000$ ). Medication non-adherence (taking $<80 \%$ of the number of prescribed pills) occurs in about $50 \%$ of newly treated hypertensive patients within the $1^{\text {st }}$ year of treatment and has been identified as the main cause of uncontrolled hypertension. Non-adherence increases the risk of uncontrolled hypertension about 5 times, as well as overall mortality, hospitalization rate, and cost of care. ${ }^{[28]}$

The impact of non-adherence is likely mediated through uncontrolled hypertension, which is known to increase the risk of stroke. ${ }^{[18]}$ It was observed that uncontrolled BP among treated hypertensive patients was moderately associated with ischemic stroke (risk ratio $=1.5$ [95\% confidence interval (CI), 1.2-1.9]) and strongly related to hemorrhagic stroke (risk ratio $=3.0$ [95\% CI, 1.7-5.4]). Our findings are also consistent with $\mathrm{Xu}$ et al. They found that $20 \%$ increment in antihypertensive medications adherence level was associated with a 9\% lower risk of stroke (RR, 0.91; 95\% CI, 0.86-0.96). ${ }^{[29]}$

The current study finding revealed that non-compliance to medication increased the odds of developing stroke and was highly significant $\left(\mathrm{MH}{ }_{\mathrm{OR}} 3.4091, P<0.000\right)$. Herttua et al. observed that in hypercholesterolemia patients with hypertension, relative to those who adhered to statins and antihypertensive therapy, the odds ratio at the year of stroke death was 7.43 (95\% CI: 5.22-10.59) for those nonadherent both to statin and antihypertensive therapy, 1.82 (95\% CI: 
Table 2: Relationship between non-compliance and risk for stroke ( $n=139$ pairs)

\begin{tabular}{|c|c|c|c|c|c|c|c|c|}
\hline \multirow[t]{2}{*}{ S. No. } & \multirow[t]{2}{*}{ Characteristics } & \multirow[t]{2}{*}{$\boldsymbol{F}$} & \multirow[t]{2}{*}{ Discordant pairs $(n)$} & \multirow{2}{*}{$\mathbf{O} \mathbf{R}_{\mathrm{MH}}$} & \multicolumn{2}{|c|}{$95 \% \mathrm{Cl}$} & \multirow[t]{2}{*}{$P$ value } & \multirow{2}{*}{$\begin{array}{l}\text { McNe mar } \\
\text { value }\end{array}$} \\
\hline & & & & & Lower limit & Upper limit & & \\
\hline \multirow[t]{5}{*}{1.} & \multicolumn{4}{|c|}{ Compliance to antihypertensive management regimen } & & & & \\
\hline & Case and control compliant & 32 & 100 & 2.8462 & 1.8205 & 4.456 & $<0.0001$ & 23.040 \\
\hline & Case and control non-compliant & 7 & & & & & & \\
\hline & Case compliant, control non-compliant & 26 & & & & & & \\
\hline & Case non-compliant, control compliant & 74 & & & & & & \\
\hline \multirow[t]{5}{*}{2.} & Compliance to medication & & & & & & & \\
\hline & Case and control compliant & 40 & 99 & 3.4091 & 2.1196 & 5.4831 & $<0.0001$ & 28.9588 \\
\hline & Case and control non-compliant & 2 & & & & & & \\
\hline & Case compliant, control non-compliant & 22 & & & & & & \\
\hline & Case non-compliant, control compliant & 75 & & & & & & \\
\hline \multirow[t]{5}{*}{3.} & Compliance to diet & & & & & & & \\
\hline & Case and control compliant & 25 & 111 & 2.0556 & 1.3803 & 3.0612 & $<0.0001$ & 13.1273 \\
\hline & Case and control non-compliant & 4 & & & & & & \\
\hline & Case compliant, control non-compliant & 36 & & & & & & \\
\hline & Case non-compliant, control compliant & 75 & & & & & & \\
\hline \multirow[t]{5}{*}{4.} & Compliance to exercise & & & & & & & \\
\hline & Case and control compliant & 23 & 108 & 3.1538 & 2.0289 & 4.9026 & $<0.0001$ & 29.037 \\
\hline & Case and control non-compliant & 8 & & & & & & \\
\hline & Case compliant, control non-compliant & 26 & & & & & & \\
\hline & Case non-compliant, control compliant & 82 & & & & & & \\
\hline \multirow[t]{5}{*}{5.} & Compliance to alcohol & & & & & & & \\
\hline & Case and control compliant & 30 & 108 & 2.6 & 1.7065 & 3.9614 & $<0.0001$ & 21.3333 \\
\hline & Case and control non-compliant & 1 & & & & & & \\
\hline & Case compliant, control non-compliant & 30 & & & & & & \\
\hline & Case non-compliant, control compliant & 78 & & & & & & \\
\hline \multirow[t]{5}{*}{6.} & Compliance to smoking & & & & & & & \\
\hline & Case and control compliant & 27 & 106 & 4.0476 & 2.5105 & 6.5258 & $<0.0001$ & 38.6415 \\
\hline & Case and control non-compliant & 6 & & & & & & \\
\hline & Case compliant, control non-compliant & 21 & & & & & & \\
\hline & Case non-compliant, control compliant & 85 & & & & & & \\
\hline
\end{tabular}

a. McNemar test is used as the number of discordant pairs are $>20 . \mathrm{OR}_{\mathrm{MH}}$ : Mantel-Haenszel odds ratio, CI: Confidence interval

1.43-2.33) for those non-adherent to statin but adherent to antihypertensive therapy, and 1.30 (95\% CI: 0.53-3.20) for those adherent to statin, but nonadherent to antihypertensive, therapy. ${ }^{[30]}$

Our study provides vital information on the importance of adherence to dietary modifications. Non-compliance to dietary modifications increases the odds of developing stroke twice among hypertensive people than those who follow the dietary modifications ( $\mathrm{MH}$ oR 2.0556, $P<0.000)$. Studies have shown that hypertensive people taking excessive salt and high fat in their diet are at risk of developing stroke. ${ }^{[27,31]}$ 
Regular planned physical activity or exercises reduce the risk factor for stroke by maintaining desirable BP level and reduce cholesterol level, triglycerides, and high blood sugar level. ${ }^{[31,32]}$ Our study finding is in agreement with this. Non-compliance to physical activity increases the risk for stroke 3 times among patients with hypertension $\left(\mathrm{MH}_{\mathrm{OR}} 3.1538, P<0.000\right)$. Many studies have shown that compliance to alcohol restrictions reduces the risk for stroke significantly and present study report that non-compliance to alcohol restrictions doubles the odds of developing stroke among hypertensive people $\left(\mathrm{MH}_{\mathrm{OR}} 2.60\right.$, $P<0.000)(31,33)$. Our study finding support the fact that risk of stroke is significantly associated with the habit of smoking $\left(\mathrm{MH}_{\mathrm{OR}} 4.0476, P<0.000\right) \cdot{ }^{[32-34]}$

\section{Strength and limitations}

Use of $\mathrm{OR}_{\mathrm{MH}}$ is the strength of our study as it controls the confounding effect if any was introduced during sample selection as it was a matched design.

Case-control studies are prone to recall bias and are a limitation of this type of studies. Second, the use of proxy respondent might have caused some error in producing accurate information. Third compliance with stress management was not assessed.

\section{Conclusion}

As hypertension is a major public health problem which needs early detection, awareness and control so that its improved detection and management can prevent strokes and heart attacks. There was a significant association between non-compliance to antihypertensive management and development of stroke. It is important to conduct an awareness program among hypertensive people regarding the importance of compliance with the treatment regimen. More consideration and care should be given to enhance the behavioral aspects of the management of hypertension to improve compliance.

\section{Conflict OF InTERest}

Authors disclaim any conflicts of interest.

\section{ReFERENCES}

1. World Health Organization (WHO). Hypertension Control. Geneva: World Health Organization; 1996.

2. Jackson G. Hypertension in Women. London (UK): Martin Dunitz Ltd.; 1996. p. 9-13.

3. Lopez A, Caselli G, Valkonen T. Adult Mortality Indeveloped Countries. New York: Oxford University Press; 1995. p. 43-5.

4. Pearson BJ, Bath PM, Spence JD. Hypertension in patients presenting with stroke. Curr Hypertens Rep 2000;2:551-7.

5. Stein AD, Stoyanovsky V, Mincheva V, Dimitrov E, Hodjeva D, Petkov A, et al. Prevalence, awareness, treatment and control of hypertension in a working Bulgarian population. Eur J Epidemiol 2000; $16: 265-70$.

6. Kuller LH. Epidemiology and prevention of stroke, now and in the future. Epidemiol Rev 2000;22:14-7.

7. Peacock E, Krousel-Wood M. Adherence to antihypertensive therapy. Med Clin North Am 2017;101:229-45.
8. Kaul S, Bandaru VC, Suvarna A, Boddu DB. Stroke burden and risk factors in developing countries with special reference to India. J Indian Med Assoc 2009;107:358, 367-70.

9. Feigin VL, Forouzanfar MH, Krishnamurthi R, Mensah GA, Connor M, Bennett DA, et al. Global and regional burden of stroke during 19902010: Findings from the global burden of disease study 2010. Lancet 2014;383:245-54

10. Feigin VL, Lawes CM, Bennett DA, Barker-Collo SL, Parag V. Worldwide stroke incidence and early case fatality reported in 56 population-based studies: A systematic review. Lancet Neurol 2009;8:355-69.

11. Leahy NM. Complications in the acute stages of stroke. Nursing's pivotal role. Nurs Clin North Am 1991;26:971-83.

12. Bronstein KS. Psychosocial components in stroke. Implications for adaptation. Nurs Clin North Am 1991;26:1007-17.

13. Langhorne P. Measures to improve recovery in the acutephase of stroke. Official J Eur Stroke Counc 1999;9 Suppl 5:2-5.

14. Lees KR, Zivin JA, Ashwood T, Davalos A, Davis SM, Diener HC, et al. NXY-059 for acute ischemic stroke. N Engl J Med 2006;354:588-600.

15. Adams HP Jr., del Zoppo G, Alberts MJ, Bhatt DL, Brass L, Furlan A, et al. Guidelines for the early management of adults with ischemic stroke: A guideline from the American heart association/ American stroke association stroke council, clinical cardiology council, cardiovascular radiology and intervention council, and the atherosclerotic peripheral vascular disease and quality of care outcomes in research interdisciplinary working groups: The American academy of neurology affirms the value of this guideline as an educational tool for neurologists. Circulation 2007;115:e478-534.

16. Du X, Cruickshank K, McNamee R, Saraee M, Sourbutts J, Summers A, et al. Case-control study of stroke and the quality of hypertension control in north west England. BMJ 1997;314:272-6.

17. Klungel OH, Stricker BH, Paes AH, Seidell JC, Bakker A, Voko Z, et al. Excess stroke among hypertensive men and women attributable to undertreatment of hypertension. Stroke 1999;30:1312-8.

18. Klungel OH, Kaplan RC, Heckbert SR, Smith NL, Lemaitre RN, Longstreth WT Jr., et al. Control of blood pressure and risk of stroke among pharmacologically treated hypertensive patients. Stroke 2000;31:420-4.

19. Iadecola C, Davisson RL. Hypertension and cerebrovascular dysfunction. Cell Metab 2008;7:476-84.

20. Gaciong Z, Siński M, Lewandowski J. Blood pressure control and primary prevention of stroke: Summary of the recent clinical trial data and meta-analyses. Curr Hypertens Rep 2013;15:559-74.

21. Boehme AK, Esenwa C, Elkind MS. Stroke risk factors, genetics, and prevention. Circ Res 2017;120:472-95.

22. Girma F, Emishaw S, Alemseged F, Mekonnen A. Compliance with anti-hypertensive treatment and associated factors among hypertensive patients on follow-up in jimma university specialized hospital, jimma, South West ethiopia: A quantitative cross-sectional study. J Hypertens 2014;3:174

23. Hashmi SK, Afridi MB, Abbas K, Sajwani RA, Saleheen D, Frossard PM, et al. Factors associated with adherence to anti-hypertensive treatment in Pakistan. PLoS One 2007;2:e280.

24. Thomas A. Factors Affecting Compliance with Anti-hypertensive Drug treatment and Required Lifestyle Modifications Among Hypertensive Patients. Pretoria: University of South Africa; 2010. p. 67-198.

25. Li WW, Wallhagen MI, Froelicher ES. Hypertension control, predictors for medication adherence and gender differences in older Chinese immigrants. J Adv Nurs 2008;61:326-35.

26. Nnaemeka R. Assessment of patient's antihypertensive medication adherence level in non-comorbid hypertension in a tertiary hospital in Nigeria. Int J Pharm Biomed Sci 2012;3:47-54.

27. Bank TW. West Bank and Gaza Update. A Quarterly Publication. West Bank and Gaza. Washington, DC: The World Bank Group; 2001.

28. Morgado M, Rolo S, Macedo AF, Pereira L, Castelo-Branco M. Predictors of uncontrolled hypertension and antihypertensive medication nonadherence. J Cardiovasc Dis Res 2010;1:196-202.

29. Xu T, Yu X, Ou S, Liu X, Yuan J, Tan X, et al. Adherence to antihypertensive medications and stroke risk: A dose-response metaanalysis. J Am Heart Assoc 2017;6:e06371. 
30. Herttua K, Martikainen P, Batty GD, Kivimäki M. Poor adherence to statin and antihypertensive therapies as risk factors for fatal stroke. J Am Coll Cardiol 2016;67:1507-15.

31. Collins R, MacMahon S. Blood pressure, antihypertensive drug treatment and the risks of stroke and of coronary heart disease. Br Med Bull 1994;50:272-98.

32. Abbott RD, Rodriguez BL, Burchfiel CM, Curb JD. Physical activity in older middle-aged men and reduced risk of stroke: The Honolulu heart program. Am J Epidemiol 1994;139:881-93.

33. Kiely DK, Wolf PA, Cupples LA, Beiser AS, Kannel WB. Physical activity and stroke risk: The Framingham study. Am J Epidemiol 1994;140:608-20

34. Donnan GA, Adena MA, O’Malley HM. Smoking as a riskfactor for cerebral ischemia. Lancet 1989;2:643-7.

How to cite this article: Ajee KL, Kshirsagar AY. Impact of Non-compliance with Antihypertensive Management on Development of Stroke among Hypertensive Patients: A Case-Control Study. Int J Nurs Med Invest. 2019;4(2):43-49 